\title{
Una regla de predicción clínica fue mejor que la impresión clínica para faringitis estreptocóccica y redujo la prescripción innecesaria de antibióticos
}

A clinical score to reduce unnecesary antibiotic use in patients with sore throat.

McIsaac WJ, White D, Tannenbaum D et al. Can Med Assoc J 1998;158:75-83

\begin{abstract}
Objetivo
Validar una regla de predicción clínica basada en signos y síntomas para identificar las infecciones de Streptococcus ß Hemolítico del grupo A (SßHGA) en pacientes de atención primaria con dolor de garganta.
\end{abstract}

\section{Diseño}

Desarrollo y validación de una regla de predicción clínica comparada con el diagnóstico de SßHGA por hisopado.

\section{Lugar}

Centro de Medicina Familiar en Canada.

\section{Pacientes}

Se incluyeron 521 pacientes $>$ de 3 años con faringitis o infección de vía aérea superior. Se excluyeron pacientes que hubieran recibido antibióticos y los inmunodeprimidos. El $70.6 \%$ fueron mujeres y el $90 \%$ adultos.

\section{Descripción del test y del gold standard (test de referencia) \\ Se utilizaron los datos de la primera mitad de los pacientes del estu- dio para desarrollar la regla, y se validó en el resto de los pacientes. Cada médico obtenía datos del paciente y realizaba un hisopado con su técnica habitual. Datos evaluados: edad, sexo, días de síntomas previos, síntomas locales y generales, fiebre, y datos del examen fí- sico como, exudado, adenopatía dolorosa, etc. El médico también asignaba la probabilidad que fuera una infección de SßHGA, y si ad- ministraba antibióticos.}

\section{Medición de resultados principales}

Sensibilidad, especificidad, coeficientes de probabilidad (likelihood ratios) para la identificación de SßHGA con la regla de predicción comparada con el cultivo.

\section{Resultados principales}

La prevalencia de SßHGA en la población fue del $13.8 \%$ (36.2\% de 3 a 14 años; $10.7 \%$ de 15 a 44; $1.3 \%$ en $\geq 45$ ). La regla tenía un puntaje de 0 a 4 . Sensibilidad del puntaje para identificar SGA total: $83.1 \%$ vs. juicio médico $69.4 \%$ ( $p=0.06$ ). Las especificidades fueron similares. En pacientes de 3 a 14 años la sensibilidad del puntaje fue mayor que la del juicio médico $(96.9 \%$ vs. $70.6, \mathrm{p}<0.05)$ y la especificidad fue mayor con el juicio médico (91.7\% vs $67.2 \%)$. La prescripción de antibióticos se hubiera reducido un $48 \%$ con las recomendaciones según el puntaje $(p<0.001)$.

Regla de predicción clínica y sugerencias de manejo según puntaje

\begin{tabular}{|c|c|c|c|c|}
\hline \multicolumn{2}{|c|}{$\begin{array}{c}\text { Paso 1: Determinar el puntaje } \\
\text { del paciente }\end{array}$} & \multicolumn{3}{|c|}{$\begin{array}{l}\text { Paso 2: Elegir el manejo apropiado según } \\
\text { el puntaje total }\end{array}$} \\
\hline Criterio & Puntos & $\begin{array}{l}\text { Puntaje } \\
\text { Total }\end{array}$ & $\begin{array}{l}\text { Probabilidad } \\
\text { de infección }\end{array}$ & \\
\hline Temperat & & . & & \multirow{2}{*}{$\begin{array}{l}\text { No cultivar ni } \\
\text { dar antibióticos }\end{array}$} \\
\hline Ausenci & & & & \\
\hline Aden & 1 & 2 & & \multirow{2}{*}{$\begin{array}{l}\text { Cultivar, } \\
\text { antibióticos sólo } \\
\text { si cultivo positivo }\end{array}$} \\
\hline & +1 & 3 & 2 & \\
\hline Edad 3-14 años & +1 & 4 & $38-63 \%$ & $\begin{array}{l}\text { Cultiva } \\
\text { cosse }\end{array}$ \\
\hline & 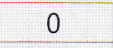 & \multirow{2}{*}{\multicolumn{3}{|c|}{$\begin{array}{l}\text { *Si el paciente tiene fiebre alta o clínicamente regular } \\
\text { y se presenta temprano en el curso de la enfermedad } \\
\text { Penicilina (eritromicina si alergia) }\end{array}$}} \\
\hline Edad $\geq 45$ años & -1 & & & \\
\hline
\end{tabular}

Conclusiones

Un puntaje clínico que toma en cuenta la edad del paciente identifica la infección por SGA mejor que el juicio médico. Esto podría reducir la cantidad de hisopados y la prescripción innecesaria de antibióticos.

\section{COMENTARIO}

El dolor de garganta agudo es un cuadro altamente prevalente en atención primaria. Es una patología de buen pronóstico, autolimitada y en la gran mayoría de los casos es de etiólogía viral. La faringitis aguda causada por el estreptococo ß hemolítico del grupo A es la única que se beneficia con el tratamiento antibiótico, dado que acorta el período sintomático 24 horas, corta la cadena epidemiógica y disminuye las complicaciones supurativas y no supurativa en la población susceptible (niños y adolescentes < de 18 años).

De todos los casos de faringitis aguda que se presentan en un consultorio de atención primaria, la prevalencia de faringitis estreptocóccica varía según la edad de la población desde un $5 \%$ en los adultos a un $10-15 \%$ en niños > de 3 años.

Dada la baja sensibilidad y especificidad del exámen físico para el diagnóstico difencial de faringitis viral y estreptocóccica, está recomendado, al menos en adultos, utilizar reglas de predicción para mejorar el rendimiento diagnóstico del exámen clínico (1). No se reco- mendaba el uso en niños dado que si bien había reglas de predicción diseñadas para niños no estaban validadas o no tenían la suficiente validez externa para utilizarlas.

Este trabajo está diseñado para desarrollar y validar una regla de predicción que se pueda utilizar tanto en niños como en adultos. Metodológicamente es un trabajo de buena calidad lo que le da una buena validez interna. Desafortunadamente, como figura en la discusión, no tuvo la suficiente cantidad de niños para poder generalizar su uso a la población pediátrica.

Una critica al trabajo es la conducta sugerida de manejo y tratamiento a pacientes adultos con probabilidades intermedias de faringitis estreptocóccica. En este grupo de población sin riesgo de desarrollar fiebre reumática, el riesgo de una complicación supurativa es similar al riego de una complicación alérgica al antibiótico y la necesidad de esperar el resultado del cultivo para indicar antibióticos hace que se pierda el único beneficio atribuible el tratamiento.

\section{Dr. Pablo Jinich}

Unidad de Medicina Familiar y Preventiva. Hospital Italiano de Buenos Aires. 